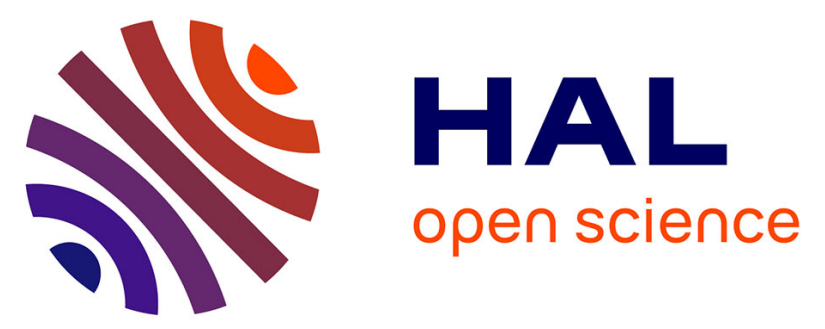

\title{
Macitentan for the treatment of portopulmonary hypertension (PORTICO): a multicentre, randomised, double-blind, placebo-controlled, phase 4 trial
}

Olivier Sitbon, Jaume Bosch, Emmanuelle Cottreel, Denes Csonka, Pascal de Groote, Marius M Hoeper, Nick H Kim, Nicolas Martin, Laurent Savale, Michael Krowka

\section{To cite this version:}

Olivier Sitbon, Jaume Bosch, Emmanuelle Cottreel, Denes Csonka, Pascal de Groote, et al.. Macitentan for the treatment of portopulmonary hypertension (PORTICO): a multicentre, randomised, double-blind, placebo-controlled, phase 4 trial. The Lancet Respiratory Medicine, 2019, 7, pp.594 604. 10.1016/S2213-2600(19)30091-8 . hal-03486263

\section{HAL Id: hal-03486263 https://hal.science/hal-03486263}

Submitted on 20 Dec 2021

HAL is a multi-disciplinary open access archive for the deposit and dissemination of scientific research documents, whether they are published or not. The documents may come from teaching and research institutions in France or abroad, or from public or private research centers.
L'archive ouverte pluridisciplinaire $\mathbf{H A L}$, est destinée au dépôt et à la diffusion de documents scientifiques de niveau recherche, publiés ou non, émanant des établissements d'enseignement et de recherche français ou étrangers, des laboratoires publics ou privés.

\section{(ㄷ)(1) $\$$}

Distributed under a Creative Commons Attribution - NonCommerciall 4.0 International 


\section{Macitentan for the treatment of portopulmonary hypertension: results from}

\section{the multicentre, randomised, double-blind, placebo-controlled PORTICO}

\section{study}

Olivier Sitbon ${ }^{1}$, Jaume Bosch ${ }^{2}$, Emmanuelle Cottreel ${ }^{3}$, Denes Csonka ${ }^{3}$, Pascal de Groote ${ }^{4}$, Marius M Hoeper $^{5}$, Nick H Kim ${ }^{6}$, Nicolas Martin ${ }^{3}$, Laurent Savale ${ }^{1}$, Michael Krowka ${ }^{7}$

1. Assistance Publique-Hôpitaux de Paris, Hôpital de Bicêtre, INSERM Unité Mixte de Recherche en Santé S_999, Université Paris-Sud, Université Paris-Saclay, Le Kremlin-Bicêtre, France

2. Hospital Clinic-IDIBAPs and CIBERehd, University of Barcelona, Barcelona, Spain, and Swiss Liver, Inselspital, Berne University, Bern, Switzerland

3. Actelion Pharmaceuticals Ltd, Allschwil, Switzerland

4. CHU Lille, Service de Cardiologie, F-59000 Lille, France, Inserm U1167, Institut Pasteur de Lille, F59000 Lille, France

5. Hannover Medical School and German Center of Lung Research, Hannover, Germany

6. University of California San Diego, La Jolla, CA, USA

7. Mayo Clinic, Rochester, MN, USA

Corresponding author: Olivier Sitbon, Service de pneumologie, Hôpital Bicêtre, 78 rue du Général Leclerc, F-94275 Le Kremlin-Bicêtre, France; olivier.sitbon@u-psud.fr; Tel: +3314521 7972

Clinical Trial registration number: NCT02382016

Target journal: Lancet Respiratory Medicine

Word limit: $3811 / 4500$ (30 refs max)

Keywords: Portopulmonary hypertension, pulmonary arterial hypertension, macitentan 


\section{Abstract (251/250 words)}

Background: There are no dedicated randomised clinical trials evaluating pulmonary arterial hypertension (PAH) therapies in patients with portopulmonary hypertension (PoPH). The endothelin receptor antagonist macitentan has demonstrated long-term efficacy in PAH with a good hepatic safety profile. PORTICO (ClinicalTrials.gov NCT02382016) evaluated efficacy and safety of macitentan in patients with PoPH.

Methods: This multicentre, prospective Phase 4 study consisted of a 12-week double-blind period (randomised 1:1 to macitentan $10 \mathrm{mg}$ or placebo), followed by a 12-week open-label period. Adult PoPH patients, with pulmonary vascular resistance (PVR) $\geq 320 \mathrm{dyn} \cdot s \cdot \mathrm{cm}^{-5}$ without severe hepatic impairment (Child-Pugh class C or model for end-stage liver disease score $\geq 19$ ) were eligible. The primary endpoint was PVR at Week 12, expressed as ratio of baseline. Safety was assessed throughout.

Findings: Eighty-five patients were randomised to macitentan $(\mathrm{N}=43)$ or placebo $(\mathrm{N}=42)$. At baseline, 63.5\% were receiving background PAH therapy. Most patients were WHO FC II/III (58.8\%/38.8\%) with mean 6MWD of $385 \mathrm{~m}$. Week 12 model-adjusted geometric means ratio for PVR was 0.65 (95\% $\mathrm{Cl} 0.59,0.72) ; p<0.0001$, representing a $35 \%$ reduction with macitentan versus placebo. During the double-blind period, adverse events (AEs) were experienced by $36(83 \cdot 7 \%)$ macitentan-treated and 33 (78.6\%) placebo-treated patients, serious AEs by 9 (20.9\%) and 6 (14.3\%), respectively. Four (9.3\%) macitentan-treated patients experienced an AE leading to discontinuation versus none in placebo. The most frequent AE during the double-blind period was peripheral oedema $(25 \cdot 6 \%$ and $11 \cdot 9 \%$, respectively).

Interpretation: Macitentan statistically-significantly improved PVR in PoPH patients, with no hepatic safety concerns.

Funding: Actelion Pharmaceuticals Ltd, Allschwil, Switzerland. 


\section{Introduction}

Portopulmonary hypertension (PoPH) is pulmonary arterial hypertension (PAH) associated with portal hypertension, which can manifest with or without cirrhosis. Data from European countries (Belgium, France, Scotland, United Kingdom and Spain) indicate that PAH prevalence ranges from approximately $6 \cdot 6-26 \cdot 0$ per million. ${ }^{1-6}$ Registry data suggest that $5-16 \%$ of patients with PAH have $\mathrm{PoPH}^{2,7,8}$ and that only $10-15 \%$ of these do not have cirrhosis. ${ }^{9-11}$ Epidemiological data regarding PoPH specifically are sparse, but in Germany, for example, point prevalence was found to be 1.2 per million adults in $2014 .^{1}$

The evidence supporting the use of PAH therapies in patients with PoPH is limited. No targeted PAH therapy has to date demonstrated efficacy in this patient population in a dedicated randomised controlled clinical trial, and almost all randomised controlled trials evaluating PAH therapies have actively excluded patients with PoPH, primarily due to concerns about using investigational treatments in individuals with hepatic complications. ${ }^{12}$ The PATENT study with riociguat included 13 patients with $\mathrm{PoPH}$, and while an analysis in this sub-group showed favourable results, there were too few patients to allow for robust conclusions. ${ }^{13}$ Small observational studies suggest improved haemodynamics and functional effects in PoPH with intravenous epoprostenol, ${ }^{14}$ inhaled iloprost, and the endothelin receptor antagonists (ERAs) ambrisentan, ${ }^{15}$ and bosentan. ${ }^{10}$ There was no indication of worsening of the underlying liver disease with these therapies, although liver enzyme elevations were noted with bosentan. ${ }^{10}$ Use of these therapies for treating PoPH in day-to-day clinical practice has therefore been based on evidence from single-centre, open-label experience. The ERA macitentan is indicated for the treatment of patients with PAH and has demonstrated longterm efficacy in patients with PAH in the large outcome-driven phase 3 SERAPHIN trial, along with a favourable hepatic safety profile. ${ }^{16,17}$ It has also been shown that there were no clinically-relevant changes in the pharmacokinetics (PK) of macitentan in non-PAH patients with mild, moderate, or severe hepatic impairment ${ }^{18}$, suggesting that dose adjustments are not necessary when treating 
patients with such impairment. However, there is no published clinical experience with the use of macitentan in PAH patients with moderate or severe hepatic impairment.

The aim of the PORTICO study was to investigate the efficacy, safety, and tolerability, as well as the PK, of macitentan in patients with PoPH in a randomised placebo-controlled study setting.

\section{Methods}

\section{Study design and participants}

PORTICO (NCT02382016) was a multicentre, randomised, double-blind, placebo-controlled, prospective, parallel group, Phase 4 study assessing the efficacy and safety of macitentan in patients with PoPH. The study was conducted in 36 centres in seven countries (Brazil, Czech Republic, France, Germany, Spain, UK and USA). The study protocol was approved by the institutional review board or independent ethics committee at each participating site and is available in the appendix. The study was completed and data obtained according to Good Clinical Practice guidelines, the principles of the Declaration of Helsinki, and the laws and regulations of the country in which each hospital was located. Written informed consent was obtained from all patients.

Patients aged $\geq 18$ years with a confirmed diagnosis of symptomatic PoPH were eligible to enter the study. Patients were required to have a 6-minute walk distance (6MWD) $\geq 50 \mathrm{~m}$ at screening. PAH was confirmed by right heart catheterization (RHC), performed within 4 weeks prior to randomisation, with mean pulmonary arterial pressure (mPAP) $\geq 25 \mathrm{mmHg}$ and pulmonary artery wedge pressure (PAWP) or left ventricular end diastolic pressure (LVEDP) $\leq 15 \mathrm{mmHg}$. Patients were required to have PVR of $\geq 4$ Wood units $\left(\geq 320 \mathrm{dyn} \cdot \mathrm{s} \cdot \mathrm{cm}^{-5}\right)$.

Patients could be receiving background PAH therapy including phosphodiesterase type 5 inhibitors (PDE5i), soluble guanylate cyclase (sGC) stimulators or inhaled prostanoids, provided that the dose was stable for at least 3 months prior to randomisation. Patients with previous ERA treatment were excluded. Patients were excluded if they had severe hepatic impairment (Child-Pugh class C liver disease or a model for end-stage liver disease [MELD] score $\geq 19$ ) or, in the opinion of the investigator, unstable liver disease. Written informed consent was obtained from all patients. 


\section{Randomisation and masking}

Patients were randomly assigned in a 1:1 ratio, with block sizes of 4 , via an interactive voice/web response system (by independent contract research organisation Almac) to receive either macitentan $10 \mathrm{mg}$ or matching placebo orally once a day. Randomisation was stratified by background PAH therapy (Yes/No) and by region (Europe/North America/Latin America). The randomisation list was kept strictly confidential, accessible only by authorised personnel not involved with the study conduct. All patients, investigators, study staff and monitors were blinded to treatment until study closure. Macitentan and matching placebo were visibly indistinguishable, and all patient kits were packaged identically.

\section{Procedures}

A schematic overview of the study design is provided in the appendix. During the 28-day screening period, clinical and functional assessments, laboratory testing and RHC were performed. Hepatic vein catheterisation (HVC) was carried out at centres that perform the procedure routinely. Eligible patients entered a 12-week, randomised, double-blind, placebo-controlled treatment period. This was followed by a 12-week open-label treatment period, during which all eligible patients received macitentan $10 \mathrm{mg}$. The macitentan treatment period was therefore 24 weeks for patients randomised to macitentan and 12 weeks for those randomised to placebo. Clinical assessments and laboratory tests were carried out at Weeks 4, 8, and 12 during the double-blind treatment period, and Weeks 16, 20, and 24 in the open-label treatment period. RHC and HVC were carried out at Week 12. To support consistent and accurate determination of hepatic venous pressure gradient (HVPG), the HVPG tracings were reviewed centrally, if available, both at baseline and Week 12, in patients without a transjugular intrahepatic portosystemic shunt (TIPS). Only the centrally reviewed HVPG data are reported in the results. Adverse events, serious adverse events and laboratory abnormalities were monitored throughout the study and up to 30 days after the end of treatment. The Independent Liver Safety Data Review Board (ILSDRB) reviewed patients with hepatic adverse events of special interest. 


\section{Outcomes}

The primary endpoint was relative change from baseline to Week 12 in PVR, expressed as a ratio of baseline PVR. Secondary endpoints included change from baseline to Week 12 in mean right atrial pressure (mRAP), mPAP, cardiac index, total pulmonary resistance (TPR), mixed venous oxygen saturation $\left(\mathrm{SvO}_{2}\right), \mathrm{N}$-terminal pro-brain natriuretic peptide (NT-proBNP; expressed as ratio of baseline) concentration, 6MWD and WHO functional class (FC; worsening). An exploratory analysis of change from baseline to Week 12 in HVPG was also performed, along with an exploratory posthoc analysis of the change from baseline to Week 12 in PAWP or LVEDP (whichever was reported). Other efficacy endpoints included change in WHO FC (worsening), NT-proBNP (expressed as ratio of baseline) and 6MWD from macitentan initiation (i.e., from the start of the double-blind period for patients randomised to macitentan and from the start of the open-label period for patients randomised to placebo) to the end of the open-label treatment period (the macitentan treatment period). Safety endpoints including adverse events and laboratory abnormalities were assessed throughout. Changes in MELD score and Child-Pugh classification were assessed between baseline and Week 12.

A PK sub-study was performed in patients who had received open-label macitentan for at least 4 weeks and who provided sufficient plasma samples for the evaluation of the PK profile of macitentan and its active metabolite (ACT-132577).

\section{Statistical analysis}

Sample size hypotheses were based on a pooled analysis of two bosentan studies s, $^{190}$ and a haemodynamic sub-study of macitentan, ${ }^{17}$ which suggested an approximate difference in PVR between treatments of -0.31 on a log scale (corresponds by exponentiation to 0.73 for the treatment effect, expressed as ratio of geometric means, which in turn corresponds to a $27 \%$ reduction with macitentan compared with placebo) and within group standard deviation of 0.41 on a log scale. To detect such a difference with $90 \%$ power using a two-sided $5 \%$ alpha statistical t-test 
and assuming $10 \%$ non-evaluable patients, a total of 84 patients (42 per treatment group) were required to be randomised.

Primary, secondary and exploratory efficacy analyses were conducted using the full analysis set (FAS), which included all randomised patients with a baseline PVR measurement who received at least one dose of study treatment in the double-blind treatment period. Other efficacy endpoints assessed up to the end of open-label treatment period were analysed using the macitentan-treated set. A sensitivity analysis for the primary endpoint was conducted on the per protocol set (PPS). Safety assessments were performed on the safety set, which included all patients who received at least one dose of study treatment in the double-blind treatment period; PK analyses were performed using the PK set. The analysis sets are explained in full in the appendix.

The primary endpoint of PVR and secondary endpoint of NT-proBNP concentration were expressed as ratios of baseline values (Week 12 divided by baseline), which were assumed to follow a lognormal distribution. The ratios were therefore $\log _{\mathrm{e}}$-transformed and analysed using an analysis of covariance (ANCOVA) with factors for treatment group, PAH therapy at baseline and region, and a covariate of $\log _{e}$-transformed baseline variable (PVR or NT-proBNP). The geometric means ratio (macitentan versus placebo) and its $95 \%$ confidence interval $(\mathrm{Cl})$ were obtained by exponentiation, with a significant difference between treatments confirmed if the $95 \% \mathrm{Cl}$ did not include 1 . Prespecified subgroup analyses of the primary endpoint were performed with the use of interaction tests on subgroups: PAH therapy at baseline, region, baseline WHO FC, sex, presence of oesophageal varices at baseline, baseline Child-Pugh class and age.

Secondary efficacy assessments of mRAP, mPAP, cardiac index, TPR and $\mathrm{SvO}_{2}$ were expressed as change from baseline to Week 12 and were analysed using ANCOVA with factors for treatment group, PAH therapy at baseline and region, and a covariate of the baseline variable. Worsening in WHO FC from baseline to Week 12 was analysed using an exact logistic regression model with covariates for treatment group, $\mathrm{PAH}$ therapy at baseline and region. Change from baseline to Week 12 in 6MWD was analysed using a repeated measurements model with factors for treatment group, 
timepoint, treatment-by-time interaction, PAH therapy at baseline and region, and covariates of baseline 6MWD, and WHO FC. No correction for multiple testing was applied for the secondary endpoint analyses, and therefore these analyses are considered as exploratory. Analyses of efficacy in the macitentan-treated set, and all safety and PK analyses were performed using descriptive statistics. A detailed description of imputation rules and sensitivity analyses, including a worst-case scenario analysis to account for missing data, is provided in the appendix.

For the PK endpoints, the measured individual plasma concentrations of macitentan and its active metabolite were used to obtain direct estimates of maximum plasma concentration $\left(C_{\max }\right)$ and time to $C_{\max }\left(t_{\max }\right)$. Area under the plasma concentration-time curve at steady state $\left(A \cup C_{\text {tau,ss }}\right)$ was calculated according to the linear trapezoidal rule using the measured concentration-time values above the limit of quantification (LOQ) during one dosing interval. The PK variables were calculated based on the actual blood sampling time points.

Case report form data were captured via electronic data capture (EDC using the Rave system provided by Medidata Solutions, Inc., a web-based tool). Statistical analyses were performed using Statistical Analysis System (SAS, Cary, USA) software version $9 \cdot 3$ or higher.

\section{Role of the funding source}

This study was sponsored by Actelion Pharmaceuticals Ltd (Allschwil, Switzerland). The sponsor participated in the conception and design of the study, analysis and interpretation of the data, drafting and critical revision of the report, and approved submission of the manuscript. All authors had access to the data, reviewed and edited the manuscript, approved the final draft, and were involved in the decision to submit the manuscript for publication. All authors vouch for the accuracy and completeness of the analyses and for the fidelity of this report to the study protocol. The corresponding author was involved in the trial design, collection and interpretation of the data, and prepared the first draft of the manuscript with editorial assistance funded by the sponsor. 


\section{Results}

From 23 June 2015 to 28 July 2017, 119 patients were screened for eligibility. Eighty-five patients were randomised to macitentan $(\mathrm{N}=43)$ or placebo $(\mathrm{N}=42)$ and followed for 12 weeks of double-blind treatment. Of these, $39(90 \cdot 7 \%)$ macitentan-treated patients and 41 (97.6\%) placebo-treated patients entered the 12-week open-label treatment period with macitentan (Figure 1).

Patients' baseline demographics and clinical characteristics are shown in Table 1, and were well matched between the treatment groups. NT-proBNP was $\leq 300 \mathrm{ng} / \mathrm{L}$ in 25 out of 41 patients $(61 \cdot 0 \%)$ in the macitentan group, and 29 out of 40 patients (72.5\%) in the placebo group; four patients did not have NT-proBNP data available at baseline.

At Week 12, the geometric mean ratio of baseline PVR decreased to $0.63(95 \% \mathrm{Cl} 0.58-0.67)$ in the macitentan group, corresponding to a mean (SD) decrease from baseline of $202 \cdot 1(123 \cdot 6) \mathrm{dyn} \cdot \mathrm{s} / \mathrm{cm}^{5}$, and decreased to 0.98 (95\% $\mathrm{Cl} 0.91-1.05)$ in the placebo group, corresponding to a mean (SD) decrease from baseline of $7 \cdot 2(122 \cdot 2) \mathrm{dyn} \cdot \mathrm{s} / \mathrm{cm}^{5}$. The ratio of geometric means was $0 \cdot 65(95 \% \mathrm{Cl}$ 0.59-0.72), corresponding to a $35 \%$ reduction in PVR with macitentan versus placebo, $p<0.0001$;

Table 2. The geometric means ratio for all patients in shown in Figure 2. The results were consistent when the primary endpoint was assessed in predefined subgroups, including in patients receiving PAH therapy at baseline (Figure 3). The treatment effect was also consistent when sensitivity analyses were performed, including analyses in the PPS, on observed data, and using a worst-case scenario approach to account for missing data (appendix).

Secondary cardiopulmonary endpoints are shown in Table 2. At Week 12, there was a placebocorrected decrease in mPAP of $-6.0 \mathrm{mmHg}(95 \% \mathrm{Cl}:-8 \cdot 4,-3 \cdot 6)$ and TPR of $-171.5 \mathrm{dyn} \cdot \mathrm{s} \cdot \mathrm{cm}^{-5}(95 \%$ $\mathrm{Cl}:-223 \cdot 7,-119 \cdot 3$ ) with macitentan (both $p<0 \cdot 0001$ ). Change from baseline to Week 12 in cardiac index was greater in patients receiving macitentan, with a treatment effect $(95 \% \mathrm{Cl})$ of $0.5 \mathrm{~L} / \mathrm{min} / \mathrm{m}^{2}$ $(0 \cdot 2,0 \cdot 8)(p=0 \cdot 0009)$. There was no difference between treatment groups in the change from baseline to Week 12 in mRAP, $\mathrm{SvO}_{2}$ and NT-proBNP (Table 2). There was no observed treatment effect in 6MWD and WHO FC at Week 12 (Table 2). 
In a post-hoc exploratory analysis, at Week 12 , patients receiving macitentan had a mean PAWP/LVEDP (SD) of $11 \cdot 4(4 \cdot 2) \mathrm{mmHg}$ with a mean (SD) change from baseline of $2 \cdot 1(3 \cdot 7) \mathrm{mmHg}$. Mean PAWP/LVEDP (SD) was 9.4 (3.1) mmHg at Week 12 and mean (SD) change from baseline was $0.3(3.4) \mathrm{mmHg}$ in the placebo group. The treatment difference based on the change from baseline to Week 12 was $2 \cdot 4(95 \% \mathrm{Cl}: 0 \cdot 8,4 \cdot 0) \mathrm{mmHg}$.

Other efficacy endpoints of change from macitentan initiation (in the double-blind or open-label treatment periods) to the end of the macitentan treatment period (Week 24) in NT-proBNP, WHO FC and 6MWD are shown in the appendix. The overall observed change in GMWD during the doubleblind and open-label treatment periods is shown in Figure 4.

A PK sub-study was performed in ten patients treated with open-label macitentan for at least 4 weeks. The majority were male ( $n=7)$, with a mean (SD) age of $54.9(8.6)$ years. The overall geometric mean (CV \%) $C_{\max }$ was $368.6(26.0) \mathrm{ng} / \mathrm{mL}$ for macitentan with a median $\mathrm{t}_{\max }$ of 6.5 hours, and overall geometric mean (CV \%) AUC $\mathrm{C}_{\text {tau,ss }}$ of $6655 \cdot 4(32 \cdot 2) \mathrm{h} * \mathrm{ng} / \mathrm{mL}$. The geometric mean (CV \%) of the trough concentration (coefficient of variation) was $200 \cdot 2(38.0) \mathrm{ng} / \mathrm{mL}$ for macitentan and 711.5 (30.8) ng/mL for ACT-132577. The PK findings for macitentan and its active metabolite ACT132577 are provided in the appendix.

The adverse events reported most frequently and number of adverse events leading to discontinuation during the double-blind and macitentan treatment periods, are shown in Table 3. During the double-blind period, the most frequent adverse events in the macitentan group $(n=43)$ versus the placebo group $(n=42)$ were peripheral oedema (11 [25.6\%] vs 5 [11.9\%] patients), headache (7 [16.3\%] vs $7[16 \cdot 7 \%])$, and bronchitis (4 [9.3\%] vs 0). At least one serious adverse event was reported in nine (20.9\%) patients treated with macitentan and six (14.3\%) patients receiving placebo. Of the patients on macitentan, four experienced an adverse event leading to premature treatment discontinuation; these were hypersensitivity, alveolitis, PAH worsening and anaemia (one patient each). In the placebo group, one patient discontinued treatment due to patient decision. 
There were no deaths during the double-blind period. No major changes were observed in MELD scores of Child-Pugh classification during the double-blind period (appendix).

During the double-blind treatment period the mean (SD) decrease from baseline in haemoglobin was $1.77 \mathrm{~g} / \mathrm{dL}(1.25)$ for patients randomised to macitentan and $0.04 \mathrm{~g} / \mathrm{dL}(1.25)$ for patients randomised to placebo. In the macitentan group, 12 out of 43 (27.9\%) patients experienced a haemoglobin decrease from baseline of $\geq 2 \mathrm{~g} / \mathrm{dL}$ compared with two out of 41 (4.9\%) patients receiving placebo. No patients in either group had haemoglobin levels $\leq 8 \mathrm{~g} / \mathrm{dL}$. One patient in the macitentan group experienced alanine aminotransferase/aspartate aminotransferase (ALT/AST) levels $\geq 3 \times$ upper limit of normal (ULN) associated with total bilirubin $\geq 2 \times$ ULN and increased compared with baseline levels.

The mean (SD) change from baseline to Week 12 for systolic blood pressure was $-3 \cdot 0(14 \cdot 1)$ and -0.9 (14.6) $\mathrm{mmHg}$ in the macitentan and placebo groups, respectively. The mean (SD) change for the diastolic blood pressure was $-3.3(10.6)$ and $0.0(12.5) \mathrm{mmHg}$ in the macitentan and placebo groups, respectively. For the exploratory endpoint of HVPG, the mean (SD) change from baseline to Week 12 was $-0.5(3.4) \mathrm{mmHg}$ for macitentan $(n=15)$ compared with $1.5(4.1) \mathrm{mmHg}$ for placebo $(n=11)$. The mean (SD) treatment difference was $-2 \cdot 1(3 \cdot 7) \mathrm{mmHg} ; 95 \% \mathrm{Cl},-5 \cdot 1,0 \cdot 9$.

Similar adverse events were observed during the macitentan treatment period, which included the open-label treatment period $(n=84)$. Peripheral oedema was the most frequent adverse event $(23$ [27.4\%] patients), followed by headache (16 patients [19.0\%]) and anaemia (12 patients [14.3\%]) (Table 3). Anaemia was reported as serious in two patients. One patient required blood transfusion and permanently discontinued macitentan. The second patient had iron deficiency anaemia concomitant with melaena. In total, 25 out of $84(29 \cdot 8 \%)$ patients experienced at least one serious adverse event, and 10 out of $84(11.9 \%)$ patients had an adverse event leading to macitentan discontinuation. Four patients died, with causes of death reported as hepatocellular carcinoma, pneumonia, PAH and subdural haematoma (one patient each). None of these deaths was considered by the investigators to be related to study treatment. Adverse events that commenced during the 
open-label period, displayed separately for patients initially randomised to macitentan and patients initially randomised to placebo, are shown in the appendix.

During the macitentan treatment period, 31 out of 83 patients $(37 \cdot 3 \%)$ had a haemoglobin decrease from baseline of $\geq 2 \mathrm{~g} / \mathrm{dL}$ and four out of $83(4 \cdot 8 \%)$ patients had haemoglobin levels $\leq 8 \mathrm{~g} / \mathrm{dL}$. The decrease in mean haemoglobin in the macitentan treatment period occurred within the first 8 weeks of macitentan treatment (when received as double-blind or open-label treatment) and stabilised thereafter. One further patient experienced alanine aminotransferase/aspartate aminotransferase (ALT/AST) levels $\geq 3 \times$ upper limit of normal (ULN); associated with total bilirubin $\geq 2 \times U L N$ and increased compared with baseline levels.

\section{Discussion}

PORTICO was the first randomised controlled trial of PAH therapy specifically conducted in patients with PoPH. The study met its primary endpoint showing a 35\% reduction of PVR at Week 12 with macitentan versus placebo. Some other cardiopulmonary parameters, measured as secondary endpoints, were also changed in patients treated with macitentan, including increase in cardiac index, and decrease in mPAP and TPR. Improvements were not seen in mRAP, $\mathrm{SvO}_{2}$ or NT-proBNP in this study, nor in the functional parameters of WHO FC and 6MWD. Taking into consideration the severity of portopulmonary hypertension, the underlying liver disease and comorbidities of PoPH patients, treatment with macitentan appears to be well-tolerated, with no hepatic safety concerns. Previous studies suggest that haemodynamic parameters are important prognostic indicators in patients with PoPH. ${ }^{9}$ Severe pulmonary hypertension is a contraindication for liver transplantation, and therefore haemodynamic status and improvements may be of particular relevance for PoPH patients in whom transplant is considered. ${ }^{21,22}$ While improved haemodynamics were observed, this study was not designed to show that this improvement may decrease the peri-operative risk in patients undergoing liver transplantation.

Liver dysfunction, of particular relevance in patients with $\mathrm{PoPH}$, can increase the risk of fluid retention, ${ }^{23}$ a known common side effect of ERAs. In this study, the most frequent adverse event 
was peripheral oedema, which was experienced by $27 \%$ of patients who received macitentan at some time during the study. The slight increase in mRAP and PAWP/LVEDP observed with macitentan treatment may be related to fluid retention. Macitentan increased cardiac output in PoPH patients and in some patients, may lead to the high cardiac output that is frequently observed in cirrhotic patients. The long-term clinical consequences of high cardiac output in these patients remain unclear. The apparent lack of treatment effect on SvO2 despite a significant increase in cardiac output could be influenced by the decrease in haemoglobin level (leading to an increase in peripheral oxygen extraction) and/or by a decrease in arterial oxygen saturation due to an increase in diffusion-perfusion mismatching caused by pulmonary vasodilator effect of treatment in cirrhotic patients. ${ }^{24}$ The absence of a treatment effect on NT-proBNP may also be influenced by the presence of fluid retention, as well as the low baseline NT-proBNP levels. Sixty-four percent of patients had baseline NT-proBNP level below the recognised low-risk threshold for NT-proBNP (300 ng/L) in $\mathrm{PAH}^{25}$ where there may have been little scope for improvement.

There was no apparent treatment effect with macitentan on change from baseline to Week 12 in 6MWD or WHO FC worsening. Given the large proportion of patients in WHO FC II and the extent of PAH therapy at baseline, achieving improvements in these measures of functional capacity is likely to be challenging. The findings for WHO FC should also be interpreted with caution due to the imputation used in these analyses and the small number of patients who experienced worsening in either treatment group. It is also conceivable that the study duration may have impacted the potential to observe functional improvements. With respect to $6 \mathrm{MWD}$, among patients originally randomised to macitentan and followed through to the open-label period of the study, there was $20 \mathrm{~m}$ increase in walk distance from baseline to Week 24, although with the caveat that from Week 12 onward the patients were no longer blinded to their treatment.

In this study, macitentan was well-tolerated by most patients with a similar hepatic safety profile to that observed in clinical trials with macitentan in patients with other PAH aetiologies ${ }^{17}$ or other forms of pulmonary hypertension. ${ }^{16,26}$ There was no indication of worsening of either hepatic 
function or portal hypertension, as shown by the absence of an increase in HVPG with macitentan treatment, despite the observed increase in cardiac output. In addition, the impact of macitentan on the systemic blood pressure was minimal. The most frequent adverse events experienced by patients receiving macitentan were peripheral oedema, headache and anaemia, in line with observations in other forms of PAH. Whilst decreases in haemoglobin can be associated with the use of ERAs, in patients with PoPH any decreases in haemoglobin require additional investigation due to the potential contribution of bleeding oesophageal varices.

No clinically-relevant changes in the exposure to macitentan and its active metabolite were observed in a dedicated phase 1 study in non-PAH patients with mild, moderate or severe hepatic impairment. ${ }^{18}$ Data from the PORTICO PK sub-study support this observation and were also consistent with that seen in the SERAPHIN trial in other PAH aetiologies, ${ }^{27}$ indicating that the underlying liver disease in patients with PoPH did not impact the PK of macitentan.

The limitations of the study include a relatively small number of patients, despite this being the largest population of PoPH patients included in a randomised controlled trial to date. The design of the study also excluded patients with Child-Pugh class C or MELD score $\geq 19$, and so the findings from PORTICO do not provide evidence for macitentan treatment in patients with severe or end-stage liver disease, such as those who are in immediate need of liver transplant based on their hepatic status. Finally, the relatively short duration of the study means that the findings cannot be extrapolated to long-term outcomes in PoPH patients.

In PORTICO, treatment with macitentan in patients with POPH resulted in improvement in PVR, without leading to further adverse liver conditions in patients with mildly-or moderately-impaired liver function.

\section{Research in Context}

\section{Evidence before this study}

Portopulmonary hypertension (PoPH) is pulmonary arterial hypertension (PAH) associated with portal hypertension with or without cirrhosis, and accounts for $5-16 \%$ of patients with PAH. Patients 
with PoPH have largely been excluded from clinical trials in PAH due to concerns about using investigational treatments in individuals with hepatic complications. Indeed, a search of PubMed for the terms "portopulmonary hypertension" or "porto pulmonary hypertension" with the limits of "trial", "clinical trial" or "randomised controlled trial" within the past 20 years confirmed a lack of dedicated clinical trials in patients with PoPH. Searching for "portopulmonary hypertension" or "porto pulmonary hypertension" along with the names of approved PAH therapies (including ambrisentan, bosentan, epoprostenol, iloprost, macitentan, riociguat, selexipag, sildenafil, tadalafil and treprostinil) revealed small, uncontrolled or observational studies, or a small sub-group analysis of a clinical trial. These data indicate beneficial effects of PAH therapies in patients with PoPH, and highlight the need for randomised clinical trials within this patient population.

Macitentan is an endothelin receptor antagonist which has demonstrated long-term efficacy, along with a favourable hepatic safety profile, in patients with PAH in the large outcome-driven Phase 3 SERAPHIN trial, which excluded patients with PoPH. A dedicated phase 1 trial showed that the pharmacokinetics of macitentan were not affected in non-PAH patients with mild, moderate or severe hepatic impairment. However, there is no clinical experience with the use of macitentan in PAH patients with moderate or severe hepatic impairment. We therefore conducted a randomised, controlled trial to investigate the efficacy, safety, tolerability, and pharmacokinetics, of macitentan exclusively in PoPH patients with mild or moderate hepatic impairment.

\section{Added value of this study}

This study was a multicentre Phase 4 trial, which included a randomised double-blind treatment period comparing macitentan $10 \mathrm{mg}$ with placebo, and an open-label treatment period to further explore macitentan treatment in patients with $\mathrm{PoPH}$. Macitentan resulted in a $35 \%$ reduction in pulmonary vascular resistance versus placebo after 12 weeks of treatment, along with changes in other cardiopulmonary parameters, assessed as secondary endpoints. The safety profile and pharmacokinetics of macitentan were comparable with that seen in previous clinical trials of patients with other forms of PAH. 


\section{Implications of all the available evidence}

Macitentan significantly improved patients' pulmonary vascular resistance, without leading to further adverse liver conditions in a hepatically-impaired population. Although there were no functional improvements seen over this timescale, the findings from this study indicate that macitentan may be a therapeutic option in patients with $\mathrm{PoPH}$, especially those with severely compromised haemodynamics.

\section{Data Sharing Statement}

The data sharing policy of the Sponsor is available at https://www.janssen.com/clinicaltrials/transparency. As noted on this site, requests for access to the study data can be submitted through Yale Open Data Access (YODA) Project site at http://yoda.yale.edu.

\section{ACKNOWLEDGEMENTS}

The authors would like to thank all the patients and investigators who participated in the study. The Steering Committee (SC) members were Jaume Bosch, Marius Hoeper, Michael Krowka, Hyong (Nick) Kim and Olivier Sitbon. The Independent Liver Safety Data Review Board (ILSDRB) members were Willis Maddrey, Paul Watkins, and James Freston. Statistical analysis was carried out by Nicolas Martin, with PK analysis carried out by Denes Csonka. HVPG tracings were reviewed by a member of the SC (Jaume Bosch). The ILSDRB reviewed patients with Hepatic Adverse Events of Special Interest (HAESI). Medical writing and submission support were provided by Shuna Gould, MSci, and Richard McDonald (Watermeadow Medical, an Ashfield Company), funded by Actelion Pharmaceuticals Ltd.

\section{Declaration of interests}

OS has received grants, personal fees and non-financial support from Actelion, Bayer and Merck; grants and personal fees from GSK; and personal fees from Arena Pharmaceuticals and Acceloron. JB has received grants and/or personal fees from Actelion, Biovie, BLB, Brudy, Conatus, Exallenz and Gilead, and non-financial support from Actelion. 
EC, DS, and NM are employees of Actelion Pharmaceuticals Ltd received non-financial support from Actelion.

PDG reports personal fees and non-financial support from Novartis and Vifor, personal fees from Servier, Bayer - MSD, Shire and Mylan, and non-financial support from Actelion.

$\mathrm{MMH}$ has received personal fees from Actelion, Bayer, Gilead, GSK, MSD and Pfizer, and nonfinancial support from Actelion.

NHK has received personal fees from Actelion, Arena, Bayer, Merck; grants from Bellerphon, Eiger, Gilead, Lung Biotechnology and Soni Vie; and non-financial support from Actelion.

LS has received non-financial support from Actelion.

MK has received non-financial support from Actelion. 


\section{References}

1. Hoeper MM, Huscher D, Pittrow D. Incidence and prevalence of pulmonary arterial hypertension in Germany. Int J Cardiol 2016; 203: 612-3.

2. Humbert $\mathrm{M}$, Sitbon $\mathrm{O}$, Chaouat $\mathrm{A}$, et al. Pulmonary arterial hypertension in France: results from a national registry. Am J Respir Crit Care Med 2006; 173(9): 1023-30.

3. Peacock AJ, Murphy NF, McMurray JJ, Caballero L, Stewart S. An epidemiological study of pulmonary arterial hypertension. Eur Respir J 2007; 30(1): 104-9.

4. Abenhaim L, Higenbottam T, Rich S. International primary pulmonary hypertension study. $\mathrm{Br}$ Heart J 1994; 71(3): 303.

5. Ling Y, Johnson MK, Kiely DG, et al. Changing demographics, epidemiology, and survival of incident pulmonary arterial hypertension: results from the pulmonary hypertension registry of the United Kingdom and Ireland. Am J Respir Crit Care Med 2012; 186(8): 790-6.

6. Escribano-Subias P, Blanco I, Lopez-Meseguer M, et al. Survival in pulmonary hypertension in Spain: insights from the Spanish registry. Eur Respir J 2012; 40(3): 596-603.

7. Krowka MJ, Miller DP, Barst RJ, et al. Portopulmonary hypertension: a report from the USbased REVEAL Registry. Chest 2012; 141(4): 906-15.

8. Sitbon O, Yaïci A, Rottat L, et al. The changing picture of patients with pulmonary arterial hypertension (PAH) in France. European Respiratory Journal 2011; 38(Suppl 55): 4913.

9. Le Pavec J, Souza R, Herve $P$, et al. Portopulmonary hypertension: survival and prognostic factors. Am J Respir Crit Care Med 2008; 178(6): 637-43.

10. Savale L, Magnier R, Le Pavec J, et al. Efficacy, safety and pharmacokinetics of bosentan in portopulmonary hypertension. Eur Respir J 2013; 41(1): 96-103.

11. Sithamparanathan S, Nair A, Thirugnanasothy L, et al. Survival in portopulmonary hypertension: outcomes of the United Kingdom National Pulmonary Arterial Hypertension Registry. J Heart Lung Transplant 2017; 36(7): 770-9.

12. Sitbon $\mathrm{O}, \mathrm{O}^{\prime}$ Callaghan DS, Savale L. Portopulmonary hypertension: light at the end of the tunnel? Chest 2012; 141(4): 840-2.

13. Cartin-Ceba R, Halank M, Ghofrani HA, et al. Riociguat treatment for portopulmonary hypertension: a subgroup analysis from the PATENT-1/-2 studies. Pulm Circ 2018; 8(2): 2045894018769305.

14. Krowka MJ, Frantz RP, McGoon MD, Severson C, Plevak DJ, Wiesner RH. Improvement in pulmonary hemodynamics during intravenous epoprostenol (prostacyclin): A study of 15 patients with moderate to severe portopulmonary hypertension. Hepatology 1999; 30(3): 641-8.

15. Cartin-Ceba R, Swanson K, Iyer V, Wiesner RH, Krowka MJ. Safety and efficacy of ambrisentan for the treatment of portopulmonary hypertension. Chest 2011; 139(1): 109-14.

16. Pulido T, Adzerikho I, Channick RN, et al. Macitentan and morbidity and mortality in pulmonary arterial hypertension. N Engl J Med 2013; 369(9): 809-18.

17. Galie N, Jansa P, Pulido T, et al. SERAPHIN haemodynamic substudy: the effect of the dual endothelin receptor antagonist macitentan on haemodynamic parameters and NT-proBNP levels and their association with disease progression in patients with pulmonary arterial hypertension. Eur Heart J 2017; 38(15): 1147-55.

18. Sidharta PN, Lindegger N, Ulc I, Dingemanse J. Pharmacokinetics of the novel dual endothelin receptor antagonist macitentan in subjects with hepatic or renal impairment. J Clin Pharmacol 2013; 54(3): 291-300.

19. Jais $X, D^{\prime}$ Armini $A M$, Jansa $P$, et al. Bosentan for treatment of inoperable chronic thromboembolic pulmonary hypertension: BENEFiT (Bosentan Effects in iNopErable Forms of chronlc Thromboembolic pulmonary hypertension), a randomized, placebo-controlled trial. J Am Coll Cardiol 2008; 52(25): 2127-34. 
20. Galie N, Rubin L, Hoeper M, et al. Treatment of patients with mildly symptomatic pulmonary arterial hypertension with bosentan (EARLY study): a double-blind, randomised controlled trial.

Lancet 2008; 371(9630): 2093-100.

21. DuBrock HM, Goldberg DS, Sussman NL, et al. Predictors of waitlist mortality in portopulmonary hypertension. Transplantation 2017; 101(7): 1609-15.

22. Savale L, Sattler C, Coilly A, et al. Long-term outcome in liver transplantation candidates with portopulmonary hypertension. Hepatology 2017; 65(5): 1683-92.

23. Kashani A, Landaverde C, Medici V, Rossaro L. Fluid retention in cirrhosis: pathophysiology and management. QJM 2008; 101(2): 71-85.

24. Olsson KM, Meyer K, Berliner D, Hoeper MM. Development of hepatopulmonary syndrome during combination therapy for portopulmonary hypertension. European Respiratory Journal 2019; 53(1): 1801880.

25. Galie N, Humbert M, Vachiery JL, et al. 2015 ESC/ERS Guidelines for the diagnosis and treatment of pulmonary hypertension: The Joint Task Force for the Diagnosis and Treatment of Pulmonary Hypertension of the European Society of Cardiology (ESC) and the European Respiratory Society (ERS): Endorsed by: Association for European Paediatric and Congenital Cardiology (AEPC), International Society for Heart and Lung Transplantation (ISHLT). Eur Heart J 2016; 37(1): 67-119.

26. Ghofrani HA, Simonneau G, D'Armini AM, et al. Macitentan for the treatment of inoperable chronic thromboembolic pulmonary hypertension (MERIT-1): results from the multicentre, phase 2, randomised, double-blind, placebo-controlled study. Lancet Respir Med 2017; 5(10): 785-94.

27. Issac M, Dingemanse J, Sidharta PN. Pharmacokinetics of macitentan in patients with pulmonary arterial hypertension and comparison with healthy subjects. The Journal of Clinical Pharmacology 2017; 57(8): 997-1004. 


\section{Figures and tables}

Table 1: Baseline demographic, clinical and hepatic characteristics in the full analysis set

\begin{tabular}{|c|c|c|c|c|}
\hline \multicolumn{2}{|l|}{ 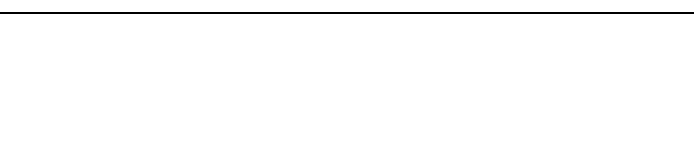 } & $\begin{array}{l}\text { Macitentan } \\
\qquad \mathrm{N}=43\end{array}$ & $\begin{array}{l}\text { Placebo } \\
\mathrm{N}=42\end{array}$ & $\begin{array}{l}\text { Total } \\
\mathrm{N}=85\end{array}$ \\
\hline \multicolumn{2}{|l|}{ Sex, male, n (\%) } & $22(51 \cdot 2)$ & $22(52 \cdot 4)$ & $44(51 \cdot 8)$ \\
\hline \multicolumn{2}{|c|}{ Age, mean (SD), years } & $58 \cdot 0(8 \cdot 7)$ & $59 \cdot 0(9 \cdot 5)$ & $58 \cdot 5(9 \cdot 1)$ \\
\hline \multicolumn{2}{|c|}{ BMI, mean (SD), kg/m² } & $29 \cdot 0(4 \cdot 8)$ & $29 \cdot 3(4 \cdot 0)$ & $29 \cdot 2(4 \cdot 4)$ \\
\hline \multirow{3}{*}{$\begin{array}{l}\text { Geographical } \\
\text { region, n (\%) }\end{array}$} & Europe & $29(67 \cdot 4)$ & $28(66 \cdot 7)$ & $57(67 \cdot 1)$ \\
\hline & North America & $12(27 \cdot 9)$ & $11(26 \cdot 2)$ & $23(27 \cdot 1)$ \\
\hline & Latin America & $2(4 \cdot 7)$ & $3(7 \cdot 1)$ & $5(5 \cdot 9)$ \\
\hline \multicolumn{2}{|c|}{$\begin{array}{l}\text { Time since PAH diagnosis, median (IQR), } \\
\text { months }\end{array}$} & $7(2,33)$ & $12(1,37)$ & $10(2,36)$ \\
\hline \multicolumn{2}{|c|}{ PAH therapy, $n(\%)$} & $27(62 \cdot 8)$ & $27(64 \cdot 3)$ & $54(63 \cdot 5)$ \\
\hline \multirow{3}{*}{ WHO FC } & $\mathrm{FCl}$ & $1(2 \cdot 3)$ & $1(2 \cdot 4)$ & $2(2 \cdot 4)$ \\
\hline & FC II & $27(62 \cdot 8)$ & $23(54 \cdot 8)$ & $50(58 \cdot 8)$ \\
\hline & FC III & $15(34.9)$ & $18(42 \cdot 9)$ & $33(38.8)$ \\
\hline \multicolumn{2}{|c|}{ 6MWD at baseline, mean (SD), $\mathrm{m}$} & $385 \cdot 8(100 \cdot 0)$ & $383 \cdot 2(108 \cdot 9)$ & $384 \cdot 5(103 \cdot 9)$ \\
\hline \multicolumn{2}{|c|}{ NT-proBNP, mean (SD), ng/L } & $488 \cdot 0(833 \cdot 1)^{*}$ & $367 \cdot 5(598 \cdot 1)^{\dagger}$ & $428 \cdot 4(724 \cdot 6)^{\S}$ \\
\hline \multirow{5}{*}{$\begin{array}{l}\text { Haemodynamic } \\
\text { characteristics, }\end{array}$} & PVR, dyn $\cdot s \cdot \mathrm{cm}^{-5}$ & $552 \cdot 4(192 \cdot 8)$ & $521 \cdot 7(163 \cdot 3)$ & $537 \cdot 2(178 \cdot 4)$ \\
\hline & $\mathrm{mPAP}, \mathrm{mmHg}$ & $46 \cdot 4(7 \cdot 9)$ & $43 \cdot 8(8 \cdot 5)$ & $45 \cdot 1(8 \cdot 3)$ \\
\hline & mRAP, $\mathrm{mmHg}$ & $7 \cdot 3(3 \cdot 7)$ & $6 \cdot 7(3.6)$ & $7 \cdot 0(3 \cdot 7)$ \\
\hline & PAWP/LVEDP, mmHg & $9 \cdot 3(3 \cdot 0)$ & $9 \cdot 8(2 \cdot 8)$ & $9 \cdot 5(2 \cdot 9)$ \\
\hline & Cardiac index, $\mathrm{L} / \mathrm{min} / \mathrm{m}^{2}$ & $3 \cdot 1(0 \cdot 8)$ & $2.9(0.8)$ & $3 \cdot 0(0 \cdot 8)$ \\
\hline
\end{tabular}




\begin{tabular}{|c|c|c|c|c|}
\hline & $\mathrm{SvO}_{2}, \%$ & $69 \cdot 2(9 \cdot 9)^{*}$ & $69 \cdot 9(5 \cdot 3)^{*}$ & $69 \cdot 5(7 \cdot 9)^{\ddagger}$ \\
\hline \multicolumn{2}{|c|}{$\begin{array}{l}\text { Time since portal hypertension diagnosis, } \\
\text { median (IQR), months }\end{array}$} & $23(5,80)$ & $31(4,69)$ & $25(5,76)$ \\
\hline \multicolumn{2}{|c|}{ Presence of oesophageal varices, $\mathrm{n}(\%)$} & $26(60 \cdot 5)$ & $28(66 \cdot 7)$ & $54(63 \cdot 5)$ \\
\hline \multicolumn{2}{|c|}{ Presence of ascites, $\mathrm{n}(\%)$} & $12(27 \cdot 9)$ & $10(23 \cdot 8)$ & $22(25 \cdot 9)$ \\
\hline \multicolumn{2}{|c|}{ MELD score**, mean (SD) } & $8 \cdot 5(2 \cdot 1)$ & $8 \cdot 4(2 \cdot 0)$ & $8 \cdot 5(2 \cdot 0)$ \\
\hline \multirow{3}{*}{$\begin{array}{l}\text { Child-Pugh } \\
\text { classification, } \\
\mathrm{n}(\%)\end{array}$} & $A($ mild $)$ & $20(46 \cdot 5)$ & $17(40 \cdot 5)$ & $37(43 \cdot 5)$ \\
\hline & B (moderate) & $3(7 \cdot 0)$ & $8(19 \cdot 0)$ & $11(12 \cdot 9)$ \\
\hline & Not classified & $20(46 \cdot 5)$ & $17(40 \cdot 5)$ & $37(43 \cdot 5)$ \\
\hline \multicolumn{2}{|c|}{ HVPG" $^{\prime \prime}$ mmHg, mean (SD) } & $9 \cdot 8(3 \cdot 6)$ & $9 \cdot 5(4 \cdot 2)$ & $9 \cdot 6(3 \cdot 9)$ \\
\hline \multirow{8}{*}{$\begin{array}{l}\text { Cause of portal } \\
\text { hypertension, } \\
\mathrm{n}(\%)\end{array}$} & Cirrhosis alcoholic & $24(55 \cdot 8)$ & $18(42 \cdot 9)$ & $42(49 \cdot 4)$ \\
\hline & Hepatitis C & $9(20.9)$ & $8(19 \cdot 0)$ & $17(20 \cdot 0)$ \\
\hline & $\begin{array}{l}\text { Cirrhosis alcoholic }+ \text { viral } \\
\text { hepatitis }\end{array}$ & $3(7 \cdot 0)$ & $8(19 \cdot 0)$ & $11(12 \cdot 9)$ \\
\hline & Metabolic causes & $2(4 \cdot 6)$ & $5(11.9)$ & $7(8 \cdot 2)$ \\
\hline & Autoimmune hepatitis & $3(7 \cdot 0)$ & $1(2 \cdot 4)$ & $4(4 \cdot 7)$ \\
\hline & Biliary cirrhosis primary & $1(2 \cdot 3)$ & $1(2 \cdot 4)$ & $2(2 \cdot 4)$ \\
\hline & Hepatitis B & 0 & $1(2 \cdot 4)$ & $1(1 \cdot 2)$ \\
\hline & Other $^{\ddagger \neq}$ & $1(2 \cdot 3)$ & $0(0 \cdot 0)$ & $1(1 \cdot 2)$ \\
\hline
\end{tabular}

6MWD, 6-minute walk distance; BMI, body mass index; HVPG, hepatic venous pressure gradient; LVEDP, left ventricular end diastolic pressure; MELD, model for end-stage liver disease; mPAP, mean pulmonary arterial pressure; mRAP, mean right atrial pressure; NT-proBNP, N-terminal pro-brain natriuretic peptide; PAH, pulmonary arterial hypertension; PAWP, pulmonary artery wedge pressure; PVR, pulmonary vascular resistance; $\mathrm{SD}$, standard deviation; $\mathrm{SvO}_{2}$, mixed venous oxygen saturation; WHO FC, World Health Organisation functional class. 
${ }^{*}$ Total $n=41 ;{ }^{\dagger}$ Total $n=40 ;{ }^{\S}$ Total $n=81 ;{ }^{\ddagger}$ Total $n=82 ; * *$ MELD score calculated post-hoc based on the relevant available information. Macitentan $n=42$, placebo $n=42$; ${ }^{9}$ Macitentan $n=28$, placebo $n=27$; ${ }^{\ddagger \ddagger}$ ○ther’ category included one patient with cryptogenic cirrhosis. 
Table 2: Change in haemodynamic parameters, NT-proBNP concentrations and clinical parameters during the double-blind treatment period in the full analysis set

\begin{tabular}{|c|c|c|c|c|c|c|}
\hline \multirow[b]{2}{*}{ Endpoints } & \multicolumn{2}{|c|}{ Macitentan group $(n=43)$} & \multicolumn{2}{|c|}{ Placebo group ( $n=42)$} & \multirow[b]{2}{*}{$\begin{array}{l}\text { Treatment effect } \\
\qquad(95 \% \mathrm{CL})\end{array}$} & \multirow[b]{2}{*}{ p-value } \\
\hline & $\begin{array}{l}\text { Baseline } \\
\text { Mean (SD) }\end{array}$ & $\begin{array}{c}\text { Change from } \\
\text { baseline to Week } \\
12 \\
\text { Mean (SD) }\end{array}$ & $\begin{array}{l}\text { Baseline } \\
\text { Mean (SD) }\end{array}$ & $\begin{array}{c}\text { Change from } \\
\text { baseline to Week } \\
12 \\
\text { Mean (SD) }\end{array}$ & & \\
\hline $\begin{array}{l}\text { PVR (primary } \\
\text { endpoint), } \\
\text { dyn } \cdot s \cdot \mathrm{cm}^{-5}\end{array}$ & $\begin{array}{l}552 \cdot 4 \\
(192 \cdot 8)\end{array}$ & $\begin{array}{c}\text { Ratio of baseline: } \\
0.63(95 \% \mathrm{Cl}: 0.58 \\
0.67)\end{array}$ & $521 \cdot 7(163 \cdot 3)$ & $\begin{array}{c}\text { Ratio of baseline: } \\
0.98 \text { (95\% Cl: } 0.91 \\
1.05)\end{array}$ & $\begin{array}{c}0.65^{*} \\
(0 \cdot 59,0 \cdot 72)\end{array}$ & $<0.0001$ \\
\hline mRAP, mmHg & $7 \cdot 3(3 \cdot 7)$ & $1.6(5 \cdot 6)$ & $6 \cdot 7(3.6)$ & $0 \cdot 3(3 \cdot 3)$ & $\begin{array}{c}1 \cdot 67^{\S} \\
(-0 \cdot 10,3 \cdot 44)\end{array}$ & 0.064 \\
\hline $\mathrm{mPAP}, \mathrm{mmHg}$ & $46 \cdot 4(7 \cdot 9)$ & $-6 \cdot 4(4 \cdot 9)$ & $43 \cdot 8(8 \cdot 5)$ & $0.4(7 \cdot 0)$ & $\begin{array}{c}-5.99^{\S} \\
(-8 \cdot 40,-3 \cdot 57)\end{array}$ & $<0.0001$ \\
\hline $\begin{array}{l}\text { Cardiac Index, } \\
\mathrm{L} / \mathrm{min} / \mathrm{m}^{2}\end{array}$ & $3 \cdot 1(0 \cdot 8)$ & $0.6(0.8)$ & $2.9(0.8)$ & $0.1(0.6)$ & $\begin{array}{c}0.52^{\S} \\
(0 \cdot 22,0 \cdot 81)\end{array}$ & 0.0009 \\
\hline$T P R$, dyn.s.cm ${ }^{-5}$ & $\begin{array}{l}689 \cdot 3 \\
(228 \cdot 6)\end{array}$ & $-199 \cdot 8(163 \cdot 1)$ & $671 \cdot 5(199 \cdot 7)$ & $-18 \cdot 3(135 \cdot 3)$ & $\begin{array}{l}-171 \cdot 48^{\S} \\
(-223 \cdot 67 \\
-119 \cdot 30)\end{array}$ & $<0.0001$ \\
\hline $\mathrm{S}_{\mathrm{V}} \mathrm{O}_{2}, \%$ & $69 \cdot 2(9 \cdot 9)^{* *}$ & $1 \cdot 1(6 \cdot 7)$ & $69 \cdot 9(5 \cdot 3)^{* *}$ & $0.8(7 \cdot 8)$ & $\begin{array}{c}0.03^{\S} \\
(-2 \cdot 85,2 \cdot 91)\end{array}$ & 0.98 \\
\hline $\begin{array}{c}\text { NT-proBNP, } \\
\text { ng/L }\end{array}$ & $\begin{array}{c}488 \cdot 0 \\
(833 \cdot 1)^{* *}\end{array}$ & $\begin{array}{c}-30 \cdot 8(722 \cdot 7) \\
\text { Ratio of baseline }{ }^{\dagger}: \\
0.86 *(95 \% \mathrm{Cl}: \\
0.67,1 \cdot 11)\end{array}$ & $367 \cdot 5^{+\dagger}(598 \cdot 1)$ & $\begin{array}{c}-63.5(476 \cdot 2) \\
\text { Ratio of baseline }^{\dagger}: \\
1.04 *(95 \% \mathrm{Cl}: \\
0.81,1 \cdot 34)\end{array}$ & $\begin{array}{c}0.87^{*} \\
(0 \cdot 64,1 \cdot 20)\end{array}$ & 0.40 \\
\hline $\begin{array}{l}\text { 6MWD } \\
\text { M }\end{array}$ & $\begin{array}{l}385 \cdot 8 \\
(100.0)\end{array}$ & $6 \cdot 4(65 \cdot 7)$ & $383 \cdot 2(108 \cdot 9)$ & $-2 \cdot 4(43 \cdot 7)$ & $\begin{array}{c}9 \cdot 73^{* * *} \\
(-14 \cdot 50,34 \cdot 0)\end{array}$ & $0 \cdot 43$ \\
\hline
\end{tabular}




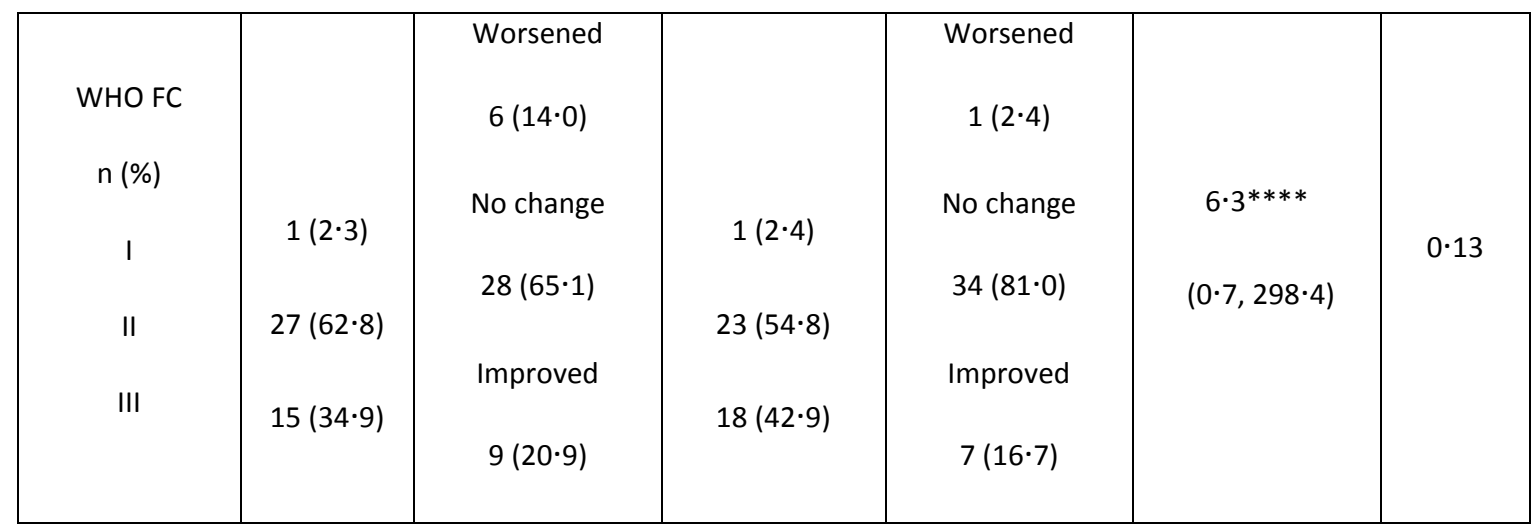

mPAP, mean pulmonary arterial pressure; mRAP, mean right atrial pressure; PVR, pulmonary vascular resistance; $\mathrm{SvO}_{2}$, mixed venous oxygen saturation; TPR, total pulmonary resistance. *The treatment effect expressed as the macitentan:placebo ratio of geometric means $(95 \% \mathrm{Cl})$ was calculated by analysis of covariance on the log-transformed ratio of baseline, with factors for treatment, randomisation stratification factors (region and PAH background therapy) and the logtransformed baseline variable (PVR or NT-proBNP) as covariate. For pulmonary vascular resistance (primary endpoint) and NT-proBNP concentration (secondary endpoint), changes were expressed as a ratio of the baseline (geometric mean $[95 \% \mathrm{Cl}]$ ).

${ }^{\S}$ The treatment effect expressed as the least-squares mean difference (macitentan minus placebo) was calculated by analysis of covariance on the change from baseline, with factors for treatment, randomisation stratification factors (region and PAH background therapy) and variable at baseline as covariate.

$* * n=41 ;{ }^{++} \mathrm{n}=40 ;{ }^{n} \mathrm{n}=39$.

***The treatment effect expressed as the least-squares mean difference (macitentan minus placebo) was calculated by a repeated measurements model with factors for treatment group, time point, treatment by time interaction, background $\mathrm{PAH}$-specific therapy at baseline and region, and covariates for baseline 6MWD and WHO functional class.

****The treatment effect expressed as odds ratio (macitentan over placebo) was calculated by an exact logistic regression with treatment, background PAH therapy, region as factors in the model. Four (out of the six) macitentan patients who worsened were due to imputation (LOCF). 
Table 3: Most frequent adverse events in the double-blind and macitentan treatment periods in the safety analysis set)

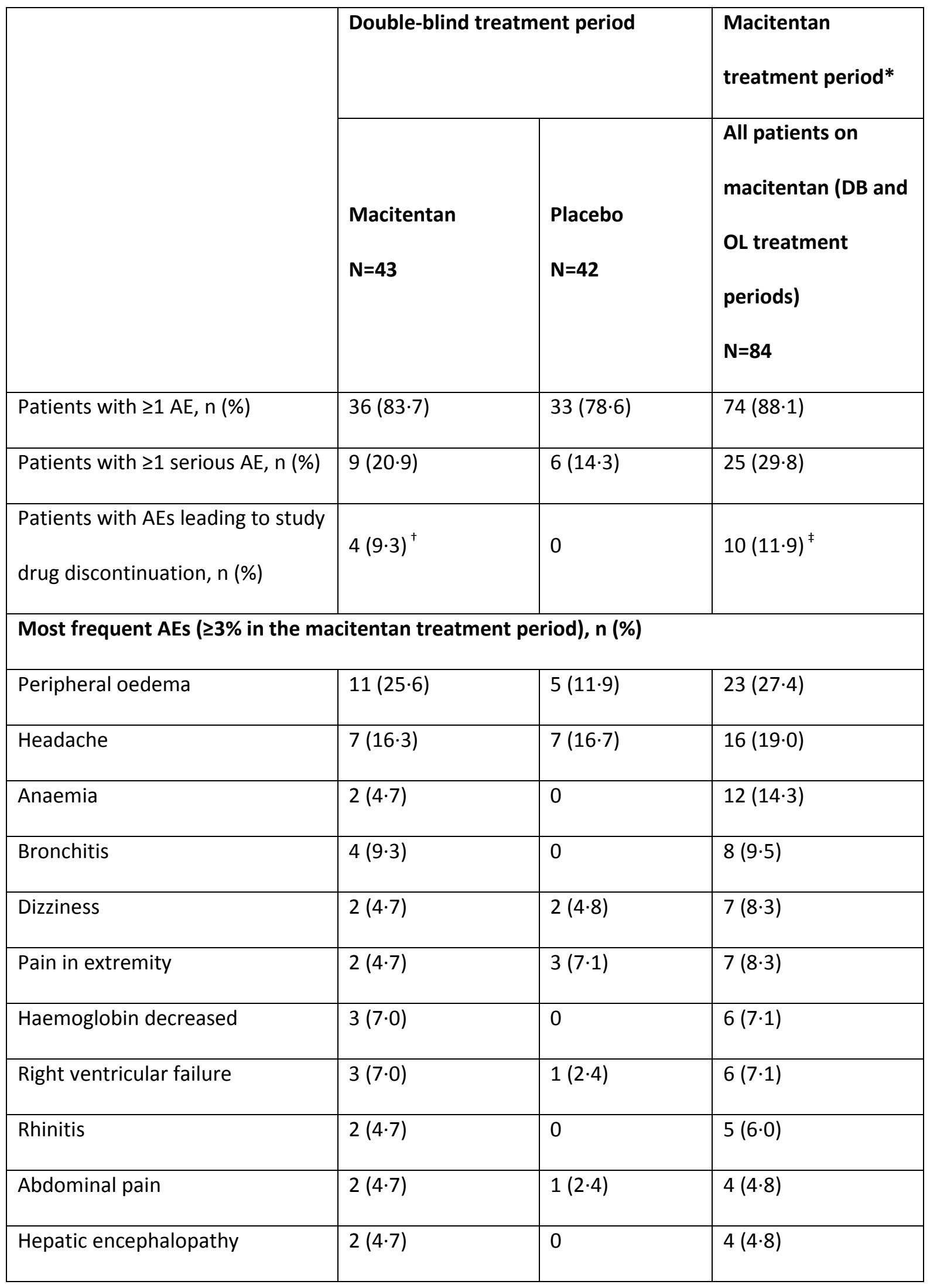




\begin{tabular}{|c|c|c|c|}
\hline Hypotension & $2(4 \cdot 7)$ & 0 & $4(4 \cdot 8)$ \\
\hline $\begin{array}{l}\text { Viral upper respiratory tract } \\
\text { infection }\end{array}$ & $2(4 \cdot 7)$ & $1(2 \cdot 4)$ & $4(4 \cdot 8)$ \\
\hline Ascites & $1(2 \cdot 3)$ & 0 & $4(4 \cdot 8)$ \\
\hline Dyspnoea & $1(2 \cdot 3)$ & $2(4 \cdot 8)$ & $4(4 \cdot 8)$ \\
\hline Nausea & $1(2 \cdot 3)$ & $2(4 \cdot 8)$ & $4(4 \cdot 8)$ \\
\hline Asthenia & 0 & $1(2 \cdot 4)$ & $4(4 \cdot 8)$ \\
\hline Hypokalaemia & $2(4 \cdot 7)$ & $6(14 \cdot 3)$ & $3(3 \cdot 6)$ \\
\hline Muscle spasms & 0 & $5(11 \cdot 9)$ & $3(3 \cdot 6)$ \\
\hline Acute kidney injury & $2(4 \cdot 7)$ & $1(2 \cdot 4)$ & $3(3 \cdot 6)$ \\
\hline Fall & $2(4 \cdot 7)$ & 0 & $3(3 \cdot 6)$ \\
\hline Urinary tract infection & $2(4 \cdot 7)$ & 0 & $3(3 \cdot 6)$ \\
\hline Arthralgia & $1(2 \cdot 3)$ & $1(2 \cdot 4)$ & $3(3 \cdot 6)$ \\
\hline Iron deficiency anaemia & $1(2 \cdot 3)$ & 0 & $3(3 \cdot 6)$ \\
\hline Pulmonary arterial hypertension & $1(2 \cdot 3)$ & $1(2 \cdot 4)$ & $3(3 \cdot 6)$ \\
\hline Rash & $1(2 \cdot 3)$ & 0 & $3(3 \cdot 6)$ \\
\hline Vomiting & $1(2 \cdot 3)$ & 0 & $3(3 \cdot 6)$ \\
\hline Exertional dyspnoea & 0 & 0 & $3(3 \cdot 6)$ \\
\hline Influenza like illness & 0 & 0 & $3(3 \cdot 6)$ \\
\hline Pruritus & 0 & $1(2 \cdot 4)$ & $3(3.6)$ \\
\hline
\end{tabular}

$\mathrm{AE}$, adverse event; $\mathrm{DB}$, double-blind; OL, open-label.

*The macitentan treatment period was 24 weeks for patients randomised to macitentan and 12 weeks for patients randomised to placebo.

${ }^{\dagger}$ Four patients had AEs starting during DB and leading to study treatment discontinuation:

Hypersensitivity; Alveolitis; PAH worsening; Anaemia (this patient discontinued the study treatment and the study during the $\mathrm{OL}$ period). 
${ }^{\ddagger}$ Six patients had AEs leading to study treatment discontinuation in the OL period: Pneumonia (this patient discontinued the study due to death); Liver function test increased (ex-placebo; this patient discontinued the study due to death from hepatocellular carcinoma); Diarrhoea (ex-placebo; this patient withdrew from the study); Anaemia (ex-placebo); Oedema peripheral (ex-placebo); Oedema peripheral and Ascites (ex-placebo; this patient withdrew from the study). 


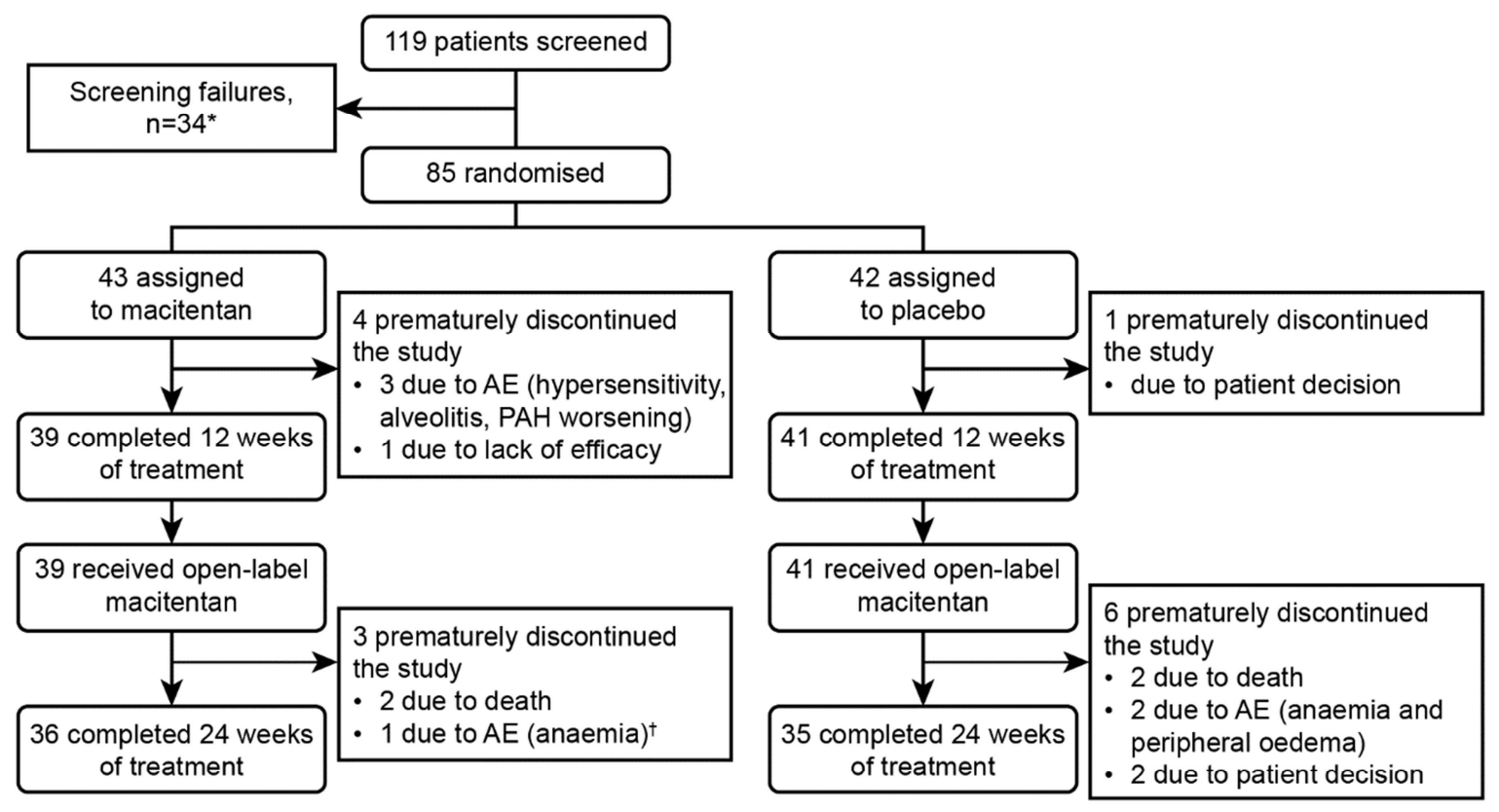

*32 patients had a screening failure and 2 patients withdrew consent. AE, adverse event

${ }^{+}$This event started during the double-blind period; however, due to this AE the patient discontinued study treatment and the study during the open-label period. 
Figure 2: PVR at Week 12 expressed as ratio of baseline in the full analysis set

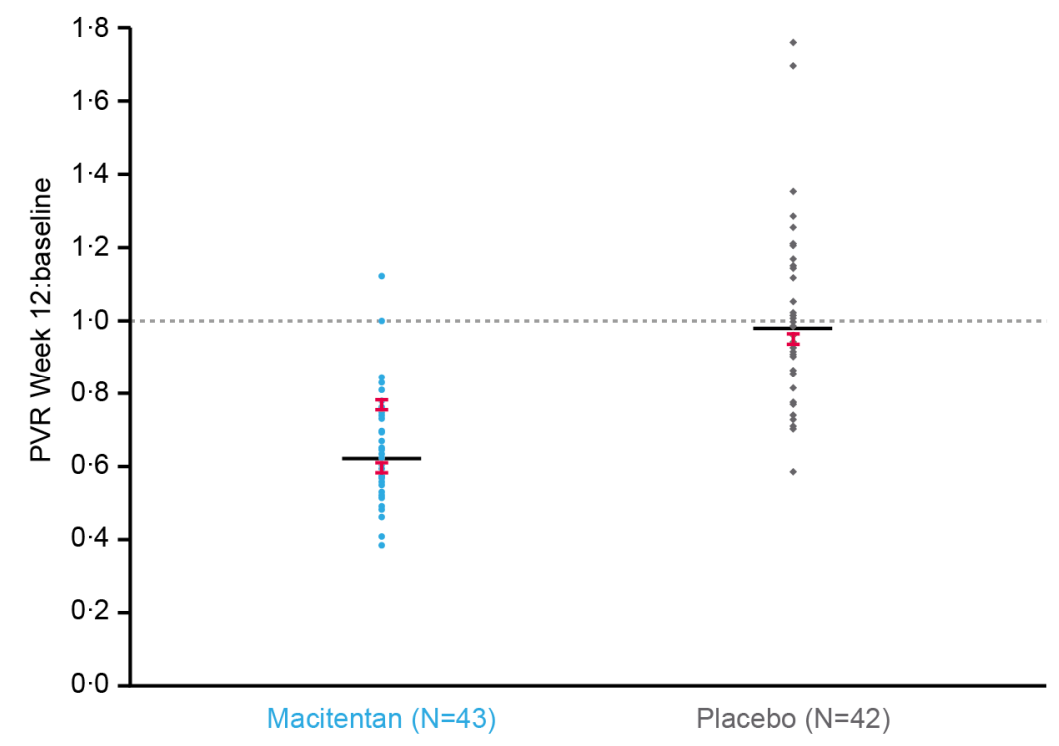

Model-adjusted* ratio of geometric means $(95 \% \mathrm{Cl})$ for macitentan:placebo $0.65(0.59,0 \cdot 72)$; $p<0.0001$. Horizontal lines in figure are geometric mean PVR ratio Week 12:baseline for each treatment; imputed values shown in red.

*ANCOVA model on $\log _{\mathrm{e}}$-transformed ratio of baseline PVR with factors for treatment, region and background PAH therapy and with $\log _{\mathrm{e}}$-transformed PVR at baseline as a covariate. ANCOVA, analysis of covariance; PAH, pulmonary arterial hypertension; PVR, pulmonary vascular resistance. 
Figure 3: Effect of macitentan on the primary endpoint by prespecified subgroups in the full analysis set

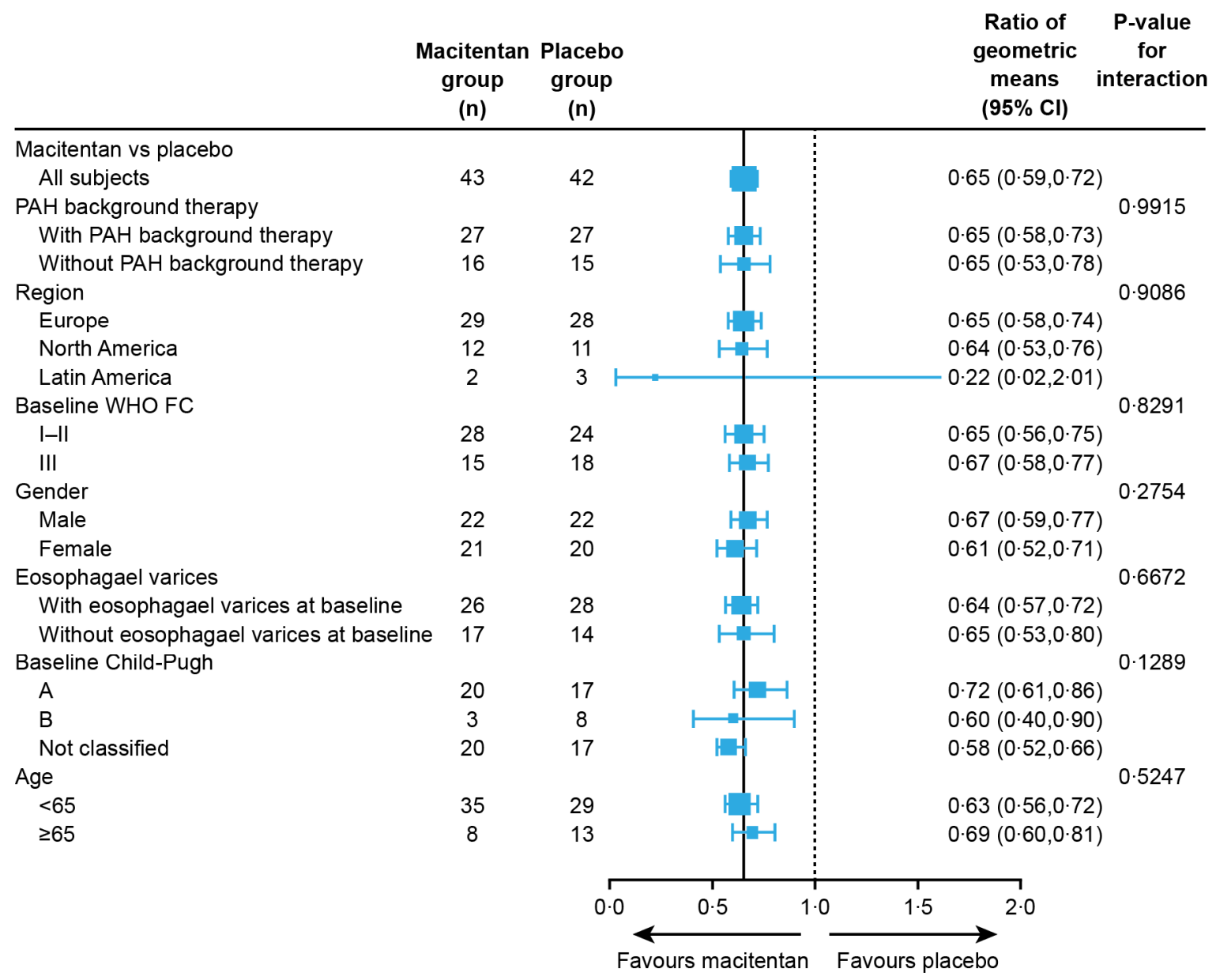

The vertical solid line references the overall treatment effect. The vertical dashed line shows the line of no treatment effect and is positioned at 1 as the treatment effect for the primary endpoint is expressed as the ratio of geometric means at Week 12 (macitentan over placebo). A non-significant interaction p-value indicates that the treatment effect in the subgroups is consistent with the overall treatment effect. p-values for interaction tests should be interpreted with caution due to low patient numbers in some subgroups.

PAH, pulmonary arterial hypertension; WHO FC, World Health Organisation Functional Class. 
Figure 4: Change in 6MWD (mean and 95\% Cl) during the double-blind and open-label treatment periods in the full analysis set (observed values)

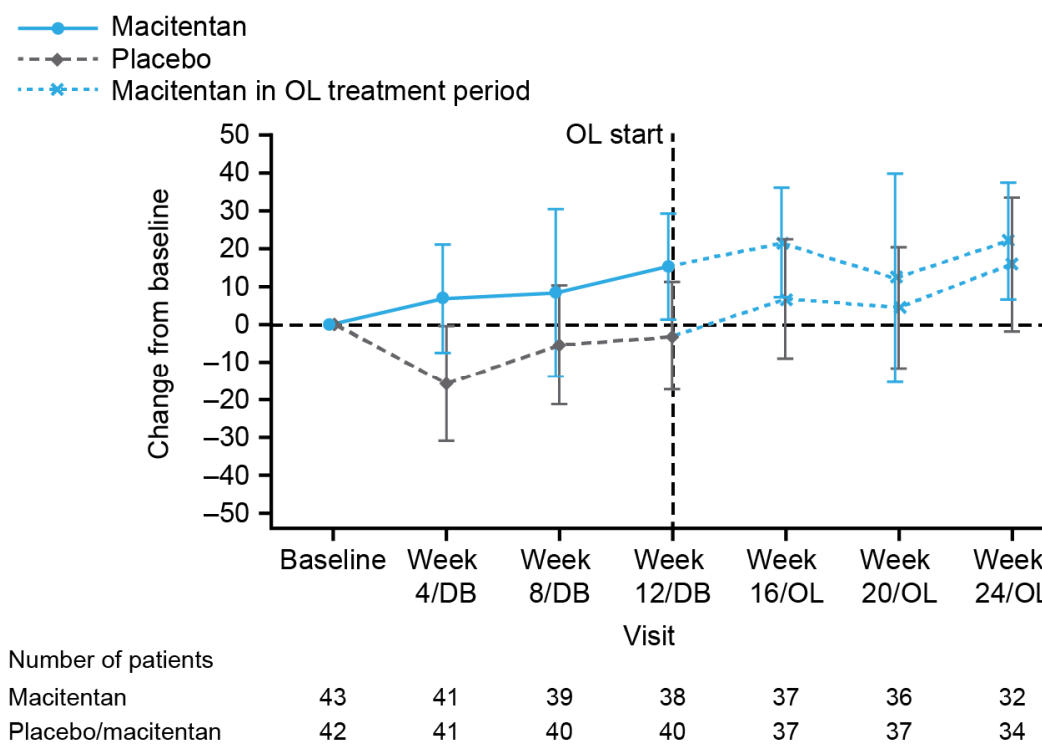

Mean change in 6MWD with confidence intervals during the double-blind and open-label treatment periods; patients who had both a baseline assessment and the relevant post-baseline assessment were included. 6MWD, 6-minute walk distance; DB, double-blind; OL, open-label. 